\title{
DESEMPENHO DE SEMENTES DE ARROZ IRRIGADO RECOBERTAS COM ZINCO ${ }^{1}$
}

\author{
CLAUDETE IZABEL FUNGUETTO², JONAS FARIAS PINTO³, LEOPOLDO BAUDET ${ }^{4}$, \\ SILMAR TEICHERT PESKE 5
}

\begin{abstract}
RESUMO - A cultura do arroz constitui um dos principais cereais que apresenta alta resposta à aplicação de zinco, sendo a cultura mais sensível à deficiência deste elemento. O objetivo nesta pesquisa foi avaliar os efeitos do recobrimento de diferentes doses de zinco em sementes de arroz irrigado, sobre o desempenho das sementes e os componentes do rendimento. O trabalho foi conduzido na Universidade Federal de Pelotas no ano agrícola de 2006/07. Os tratamentos consistiram na aplicação de uma mistura de sulfato de zinco heptahidratado $(22 \% \mathrm{Zn})$, com seis doses: zero; 0,$37 ; 0,47 ; 0,57 ; 0,67$ e $0,77 \mathrm{~g} \mathrm{~kg}^{-1}$ de semente. Além do recobrimento com sulfato de zinco, utilizou-se para todos os tratamentos uma mistura de fungicida ( $\left.3 \mathrm{~mL} \mathrm{~kg}^{-1}\right)$, polímero CF Clear ${ }^{\circledR}\left(200 \mathrm{mg} \mathrm{kg}^{-1}\right)$ e corante $\left(4 \mathrm{~mL} \mathrm{~kg}^{-1}\right)$. O delineamento experimental utilizado foi o completamente casualizado com quatro repetições. A qualidade das sementes foi avaliada por meio do teste de germinação e testes de vigor (comprimento da parte aérea e raiz, biomassa seca da parte aérea e raiz de plântulas). Em casa de vegetação foram avaliados, ainda, os componentes do rendimento (número de panículas por planta, número de grãos por panícula e peso de grãos por planta). Com base nos resultados obtiveram-se as seguintes conclusões: 1 - O recobrimento de sementes de arroz com o zinco, dosagem de $0,77 \mathrm{~g} \mathrm{~kg}^{-1}$ de semente, aumenta o número de grãos por panícula e peso de grãos por planta em condições de casa de vegetação. 2 - Sementes de arroz recobertas com zinco geram plântulas com maior crescimento. 3 - O recobrimento das sementes com zinco não afeta a germinação.
\end{abstract}

Termos para indexação: Oryza sativa L., tratamento de sementes, componentes do rendimento.

\section{PERFORMANCE OF ZINC COATED IRRIGATED RICE SEEDS}

\begin{abstract}
The rice cultivation is a major cereal that has a high response to the application of zinc, with culture more sensitive to deficiency of this element. The objective in this study was to evaluate the effects of coatings of different doses of zinc in seeds of rice, on the performance of seeds and the yield components. The work was conducted at the Federal University of Pelotas in the agricultural year of 2006/07. The treatments consisted of applying a mixture of zinc sulphate heptahydrate $(22 \% \mathrm{Zn})$, with six levels: zero; 0,$37 ; 0,47 ; 0,57 ; 0,67$ and $0,77 \mathrm{~g} \mathrm{~kg}^{-1}$ seed. In addition to coating with zinc sulphate, was used for all treatments a mixture of fungicide (3 $\left.\mathrm{mL} \mathrm{kg}^{-1}\right)$, polymer CF Clear® $\left(200 \mathrm{mg} \mathrm{kg}^{-1}\right)$ and dye $\left(4 \mathrm{~mL} \mathrm{~kg}^{-1}\right)$. The experimental design was completely randomized with four replications. Seed quality was evaluated by means of the germination test and tests of force (length of shoot and root, biomass of shoots and roots of seedlings). In a greenhouse were evaluated further the components of yield (number of panicles
\end{abstract}

\footnotetext{
${ }^{1}$ Submetido em 08/12/2008. Aceito para publicação em 19/05/2009.

${ }^{2}$ Eng. Agr., Professor Adjunto. Universidade Federal do Pampa Campus Itaqui, RS, cifunguetto@ig.com.br.
}

\footnotetext{
${ }^{3}$ Eng. Agr., Dr., Ciência e Tecnologia de Sementes. FAEM/UFPel, jfpinto@pop.com.br.

${ }^{4,5}$ Eng. Agr., Dr., Professor titular, Departamento de Fitotecnia, FAEM/ UFPel, CP. 354, CEP: 96010-970.
} 
per plant, number of grains per panicle and grain weight per plant). Based on the results it was obtained the following conclusions: 1 - The coating of rice seeds with zinc, the dosage of 0,77 $\mathrm{g} \mathrm{kg}^{-1}$ seed, increases the number of grains per panicle and weight of grains per plant under conditions of a greenhouse. 2 - Seed of rice covered with zinc generating plants with higher growth. 3 - The coating with zinc does not affect the germination.

Index terms: Oryza sativa L., seed treatment, yield components.

\section{INTRODUÇÃO}

No mundo, o arroz (Oryza sativa L.) é um dos cereais mais cultivados, especialmente na Ásia onde concentra 90\% da produção e consumo mundial de arroz, pois constitui a base alimentar da população. Aproximadamente 150 milhões de hectares são semeados anualmente e a produção atinge cerca de 600 milhões de toneladas base casca. Mais da metade dessa produção provém de lavouras com irrigação, as quais ocupam apenas $25 \%$ da área cultivada (Azambuja et al. 2004). No Brasil, 2,92 milhões de hectares foram cultivados com arroz irrigado na safra 2008/2009, um aumento de $1,7 \%$ em relação à safra 2007/08, dos quais 1,1 milhões de hectares estão no estado do Rio Grande do Sul, com produtividade média de $7.150 \mathrm{~kg}$ $\mathrm{ha}^{-1} \mathrm{um}$ aumento em relação à safra anterior de 3,6\% (Conab, 2009).

Dentre os micronutrientes, o zinco é o que mais frequentemente se mostra deficiente em solos brasileiros. Nas áreas de cultivo do Rio Grande do Sul, onde, geralmente ocorre monocultura da cultura de arroz há vários anos e em virtude da sistematização e do alagamento, do cultivo sucessivo das áreas e de outros fatores, tais como cultivares nutricionalmente exigentes, uso de fórmulas de fertilizante de elevada concentração e a falta de correção da acidez do solo faz com que ocorra deficiência de micronutriente, entre eles o mais afetado é o zinco (Marchesan et al. 2001; Silva et al. 2003).

O zinco é um nutriente importante na nutrição de plantas, presente em mais de 80 proteínas, além de ser um grande ativador enzimático, a exemplo do seu envolvimento na anidrase carbônica, dismutase de superóxido, desidrogenase de álcool e síntese do ácido indol acético (AIA) (Malavolta, 2006). Algumas proteínas são responsáveis pela transcrição do DNA, onde o zinco desempenha o papel de regular a conformação do domínio da proteína e, portanto a deficiência de zinco provoca inibição severa no crescimento das plantas (Epstein e Bloom, 2006).

Segundo Fageria e Baligar (2005), o arroz é um dos cereais que apresenta maior resposta à aplicação de zinco, sendo a cultura mais sensível à deficiência de zinco, em comparação com o milho, feijão, soja e o trigo, onde, a ausência ou deficiência deste elemento é um dos fatores limitantes na produção.

Apesar de conhecidos os reflexos negativos da carência de tais nutrientes sobre a produção, 90,2\% dos arrozeiros gaúchos não efetuam adubação com micronutrientes. Por outro lado, $8,6 \%$ fazem aplicação via solo e $1,2 \%$ via foliar (IRGA, 2008). Não há registro sobre tratamento de sementes.

É consenso entre pesquisadores de que o fornecimento do micronutriente zinco através do tratamento de sementes é a melhor forma, em virtude das pequenas quantidades exigidas pelas plantas, melhor uniformidade de distribuição, menor custo de aplicação e também garante a nutrição da planta no estágio inicial de crescimento onde o sistema radicular é pouco desenvolvido, afetando a aquisição do nutriente no solo (Boneccarrère et al. 2004).

Diante do contexto apresentado, o presente trabalho teve como objetivo avaliar os efeitos do recobrimento com diferentes doses de zinco em sementes de arroz irrigado, sobre o desempenho das sementes e os componentes do rendimento.

\section{MATERIAL E MÉTODOS}

O trabalho foi conduzido na Universidade Federal de Pelotas - RS, no ano agrícola 2006/07. No laboratório, as sementes de arroz irrigado da cultivar IRGA 417 foram submetidas ao recobrimento com sulfato de zinco heptahidratado ( $22 \%$ de $\mathrm{Zn}$ ) com seis doses: zero; 0,$37 ; 0,47$; 0,$57 ; 0,67 \mathrm{e} 0,77 \mathrm{~g} \mathrm{Zn} \mathrm{kg}^{-1}$ de sementes. Além do recobrimento com sulfato de zinco utilizou-se para todos os tratamentos uma mistura de fungicida $\left(3 \mathrm{~mL} \mathrm{~kg}^{-1}\right)$, polímero CF Clear ${ }^{\circledR}(200$ $\left.\mathrm{mg} \mathrm{kg}{ }^{-1}\right)$ e corante $\left(4 \mathrm{~mL} \mathrm{~kg}^{-1}\right)$. O volume da calda resultante da mistura dos ingredientes foi de $24 \mathrm{~mL} \mathrm{~kg}^{-1}$ de semente. A adesão da mistura foi feita manualmente, colocando a calda em sacos plásticos e posteriormente adicionou $500 \mathrm{~g}$ de sementes, agitando vigorosamente durante cerca de três minutos, em seguida, as sementes foram colocadas para secar em estufa regulada a $30{ }^{\circ} \mathrm{C}$, durante 24 horas. 
Para a avaliação do desempenho das sementes e dos componentes do rendimento, foram conduzidos os seguintes testes:

Germinação: foi realizado segundo as Regras para Análise de Sementes (Brasil, 1992), com 400 sementes por meio da semeadura de quatro subamostras de 100 sementes por tratamento, em rolo de papel Germitest umedecido com água destilada equivalente a 2,5 vezes o peso seco do papel. Os rolos foram colocados em germinadores tipo câmara regulados a temperatura ótima de $25{ }^{\circ} \mathrm{C}$. Foram realizadas duas contagens, a primeira aos sete dias e a contagem final aos quatorze dias. Os resultados foram expressos em porcentagem.

Comprimento da parte aérea e raiz de plântula: realizado conjuntamente com a primeira contagem do teste de germinação, no qual 10 plântulas normais foram retiradas aleatoriamente de cada repetição. A avaliação foi feita com o auxílio de uma régua graduada em milímetros, de acordo com a metodologia proposta por Krzyzanowski (1991), e os resultados expressos em centímetros.

Biomassa seca de parte aérea e de raiz de plântula: Dez plântulas obtidas na primeira contagem do teste de germinação de cada repetição foram separadas. Parte aérea e raiz, acondicionadas em sacos de papel e colocadas para secar em estufa de convecção de ar a $60{ }^{\circ} \mathrm{C}$, até o material atingir peso constante. A pesagem foi realizada em balança de precisão e os resultados expressos em miligramas por plântula.

Avaliação dos componentes do rendimento: Em casa de vegetação, foram cultivadas plantas em vasos plásticos com capacidade para $8 \mathrm{~kg}$ de solo, contendo $5 \mathrm{~kg}$ de solo peneirado, totalizando 24 vasos (6 tratamento x 4 repetições). A análise de solo realizada antes da instalação do experimento indicou: teor de argila: $8 \%$; índice SMP: 7,2; MO: 0,6\%; P: 8,6 mg dm${ }^{-3}$; K: 41,0 mg dm${ }^{-3}$; Zn: 11,9 $\mathrm{mg} \mathrm{dm}{ }^{-3}$. A adubação foi feita de acordo com o resultado da análise de solo e recomendações da Comissão de Química e Fertilidade do solo - RS/SC (2004), exceto para zinco. Foram semeadas dez sementes por vaso, tendo sido efetuado o raleio aos 10 dias após a emergência, permanecendo três plantas por vaso, totalizando 12 plantas por tratamento. Os vasos foram irrigados ao longo de todo o ciclo da cultura, mantendo-se constante uma lâmina de $2 \mathrm{~cm}$ de água. No momento da colheita foram avaliados os componentes do rendimento: número de panículas por planta, número de grãos por panícula e peso de grãos por planta. Foi contado o número de panículas por planta e em seguida foram retiradas manualmente as sementes, contadas, armazenadas em embalagens de papel identificadas e posteriormente pesadas em balança de precisão. O resultado referente a panículas e grãos foi expresso em unidades e o peso de grãos expresso em gramas corrigido para $13 \%$ de umidade.

O procedimento estatístico utilizado foi delineamento completamente casualisado, com quatro repetições e seis doses de zinco. A análise estatística foi realizada com programa SAS Institute (1999), e os dados de doses foram submetidos à análise de variância através do teste de $\mathrm{F}$ a $5 \%$ de probabilidade, e estudo de regressão polimonial.

\section{RESULTADOS E DISCUSSÃO}

Como o zinco é um ativador enzimático, as sementes portadoras de melhor nível de qualidade podem apresentar melhorias na germinação e no vigor, quando enriquecida com zinco (Ribeiro e Santos, 1996), porém de acordo com os resultados obtidos, constatou-se que não houve diferença significativa em relação às doses testadas e a variável germinação. A testemunha (zero $\mathrm{g} \mathrm{Zn} \mathrm{kg}^{-1}$ de sementes) apresentou uma média de $85 \%$ de germinação, já a média dos tratamentos ficou em torno $86 \%$ (Figura 1). Isto indica que a germinação das sementes recobertas com zinco não foi afetada pelo processo. Respostas semelhantes foram obtidas por Vieira e Moreira (2005) e Ohse et al. (2000). Entretanto, Slaton et al. (2001), observaram que a aplicação da dose de 1 $\mathrm{g} \mathrm{Zn} \mathrm{kg}{ }^{-1}$ de sementes, tendo como fonte o sulfato de zinco, aumentou a porcentagem de germinação das sementes de arroz em cerca de $59 \%$ depois de oito dias do início do teste de germinação, e em cerca de $50 \%$ depois de dez dias do início do mesmo teste.

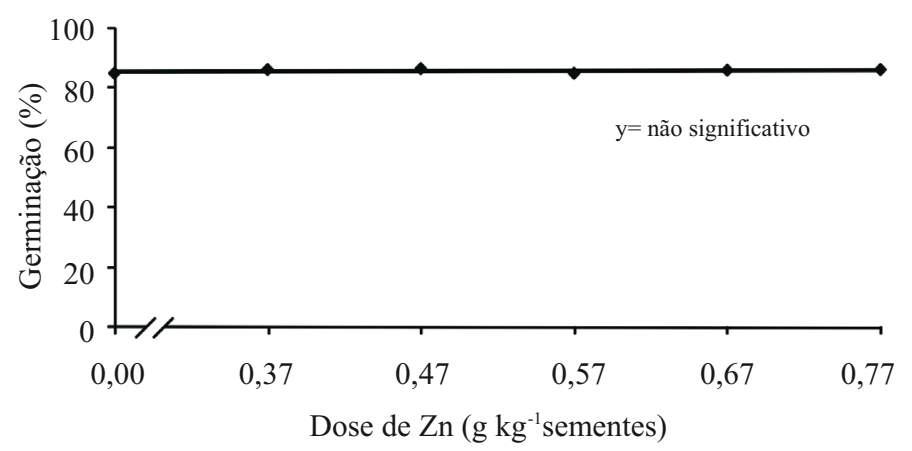

FIGURA 1. Germinação (\%) de sementes de arroz irrigado cv. 417, recobertas com diferentes doses de sulfato de zinco heptahidratado.

As diferentes doses de zinco aplicadas nas sementes apresentaram diferenças significativas entre si para o comprimento da parte aérea e raiz de plântulas de arroz 
(Figura 2). O comprimento máximo da parte aérea de plântula obtida aos sete dias foi de $8,5 \mathrm{~cm}$ na dose de $0,57 \mathrm{~g} \mathrm{Zn} \mathrm{kg-}^{-}$ ${ }^{1}$ de sementes, obtendo um aumento de $58 \%$ comparado à testemunha $(5,3 \mathrm{~cm})$. Nas doses 0,67 e $0,77 \mathrm{~g} \mathrm{Zn} \mathrm{kg}^{-1} \mathrm{de}$ sementes, verificou-se uma diminuição no comprimento da parte aérea de 7 e 13\% respectivamente, comparado a dose de $0,57 \mathrm{~g} \mathrm{Zn} \mathrm{kg}^{-1}$ de sementes. Barbosa Filho et al. (1994) e Leão (1990), os quais, estudando os efeitos da aplicação de zinco nas sementes de arroz de sequeiro, concluíram que a altura de plântulas foi significativamente maior com o fornecimento de zinco através do tratamento das sementes.

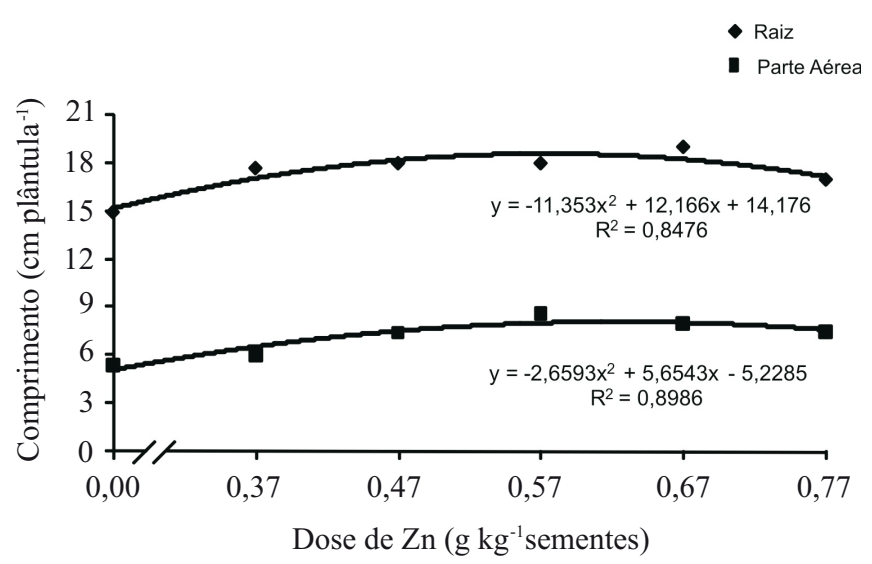

FIGURA 2. Comprimento (cm plântula $\left.{ }^{-1}\right)$ da parte aérea e raiz de plântulas de arroz irrigado cv. 417 recobertas com diferentes doses de sulfato de zinco heptahidratado.

No comprimento de raiz, verificou-se um aumento até a dose de $0,67 \mathrm{~g} \mathrm{Zn} \mathrm{kg}^{-1}$ de sementes, apresentando um incremento de $26 \%$, quando comparado a testemunha, aumento de $4 \mathrm{~cm}$ de raiz. Ohse et al. (2000), compararam diferentes tratamentos de sementes de arroz com os micronutrientes zinco, boro e cobre, no qual os maiores valores para comprimento da parte aérea e raiz de plântulas de arroz irrigado foram obtidos com zinco, com um acréscimo de 9,3\% e 5,1\% respectivamente em relação a testemunha. Na dose de $0,77 \mathrm{~g} \mathrm{Zn} \mathrm{kg}^{-1}$ de sementes, apresentou uma diminuição no comprimento de raiz, mesmo assim, o aumento foi de $13 \%$ comparado a dose zero de $\mathrm{Zn}$. Este efeito, deve-se ao fato do zinco exercer importantes funções no metabolismo das plantas, participando da síntese do aminoácido triptofano, precursor do AIA (Ácido Indol Acético) que é o principal hormônio promotor do crescimento, além de ativar várias enzimas e ser componente estrutural de outras (Favarin e Marini, 2000).
De acordo com os resultados obtidos, a produção de biomassa seca, tanto da parte aérea como da raiz de plântulas aumentou de forma linear conforme o aumento das dosagens de zinco (Figura 3). A dose de $0,77 \mathrm{~g} \mathrm{Zn} \mathrm{kg}^{-1}$ de semente, apresentou o maior acumulo da matéria seca tanto parte aérea como raiz, um aumento de 52 e $63 \%$, respectivamente, comparado a testemunha. Esta resposta positiva no aumento da biomassa seca se deve ao fato do micronutriente zinco ter um importante papel como promotor do crescimento, estando envolvido em diversas rotas metabólicas responsáveis pelo crescimento das plântulas, provocando um acréscimo na área fotossintetizante ativa, proporcionando um aumento na biomassa seca de plântulas.

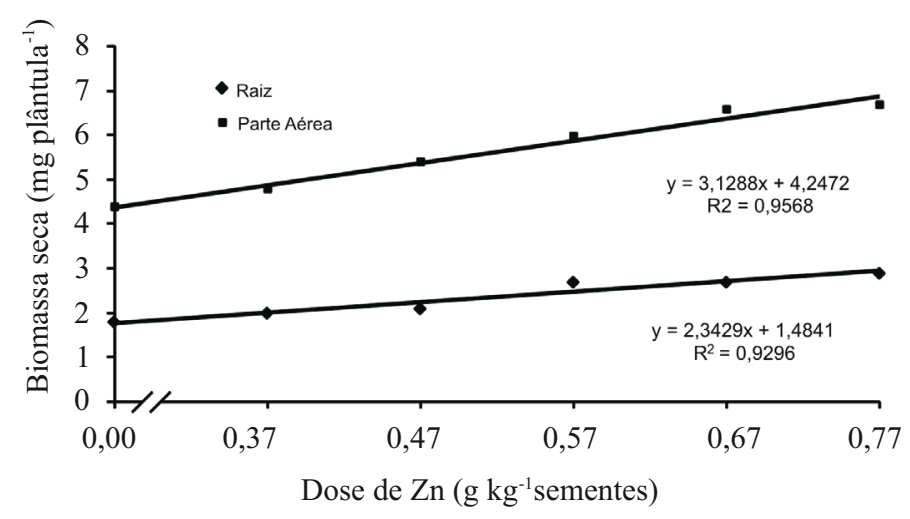

Rozane et al. (2008), observaram que a dose de $0,86 \mathrm{~g}$ de $\mathrm{Zn} \mathrm{kg}^{-1}$ de semente na forma de sulfato de zinco contribuiu significativamente para o aumento de $48 \%$ do peso da massa seca de plantas de arroz comparado a testemunha. De maneira semelhante, Oliveira et al. (2003), encontraram resposta significativa para o aumento da massa seca parte aérea e raiz de duas cultivares de arroz, quando se trabalhou com diversas doses de zinco. Entretanto, Bonnecarrère et al. (2004), trabalhando com arroz, concluíram que não houve diferença significativa em relação as doses aplicadas, para biomassa seca da parte aérea e raiz.

O número de panículas por planta obtido em casa de vegetação (Figura 4), não mostrou significância dos tratamentos sobre este parâmetro analisado. Verificou-se que a média dos resultados foi de 8 panículas por planta, independente dos tratamentos. Este resultado mostra semelhança com Bonnecarrère et al. (2004), que compararam 
o desempenho de vários genótipos de arroz irrigado, na qual constataram que o número de panículas não foi afetado pelo tratamento com zinco. Já Ohse et al. (1998), observaram que o número de panículas/planta de arroz irrigado variou em função da dose de zinco aplicada nas sementes, com número máximo estimado de 5,94 panículas/plantas para a dose ótima estimada $0,76 \mathrm{~g} \mathrm{Zn} \mathrm{kg}^{-1}$ de sementes, equivalente a $114,0 \mathrm{~g} \mathrm{ha}^{-1}$ de zinco.

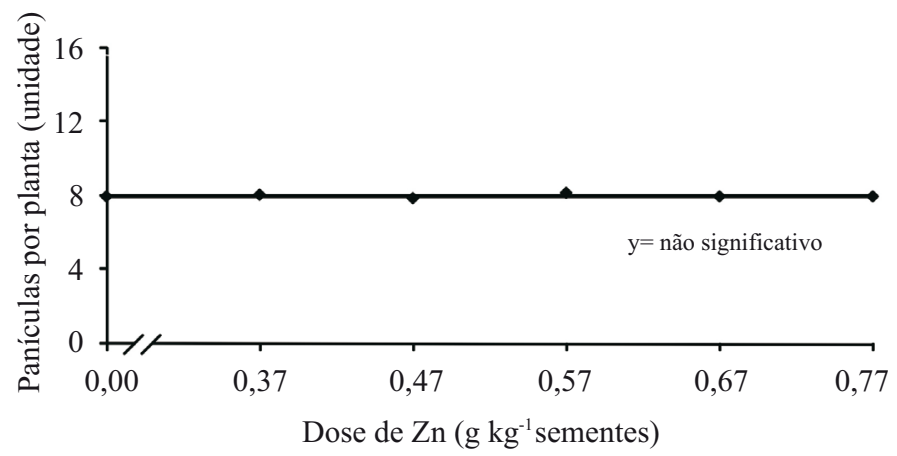

FIGURA 4. Número de panículas por planta (unidade), de arroz irrigado cv. 417, recobertas com diferentes doses de sulfato de zinco heptahidratado.

Os resultados referentes ao número de grãos por panícula e o peso de grãos por planta (Figuras 5 e 6), mostraram um aumento linear destas variáveis conforme o aumento das doses de zinco, apresentando um incremento de $29 \%$ no número de grãos por panícula e $21 \%$ no peso de grãos por planta, na dose máxima de $0,77 \mathrm{~g} \mathrm{Zn} \mathrm{kg}^{-1}$ de sementes, quando comparadas a dose zero $\mathrm{Zn} \mathrm{kg}^{-1}$ de sementes. $\mathrm{O}$ fato de a planta estar bem nutrida na fase reprodutiva, o que pode favorecer a diminuição do abortamento de grãos, ou seja, quanto melhor seu equilíbrio nutricional maior será a capacidade da planta em manter maior número de grãos, o que, consequentemente pode influenciar no peso de grãos (Lopes, 1999). Neste presente trabalho observou-se maior número de grãos chochos na dose zero $\mathrm{g} \mathrm{Zn} \mathrm{kg}^{-1}$ de sementes em comparação as demais doses, porém estes dados não foram contabilizados.

Considerando o coeficiente de determinação das regressões superior a 9, das variáveis, número de grãos por panícula e peso de grãos por planta, constata-se, que os resultados do recobrimento das sementes de arroz com zinco propiciam um aumento de produtividade superior a $20 \% \mathrm{em}$ condições controladas de casa de vegetação, indicando que isso possa ocorrer em lavouras comerciais de produção de arroz. Diversos autores verificaram aumento na produção de grãos de arroz com a aplicação de zinco nas sementes, além de ser o micronutriente com maior correlação entre doses e produtividade de grãos de arroz (Lopes, 1999; Moraes et al. 2004; Boneccarrère et al. 2004).

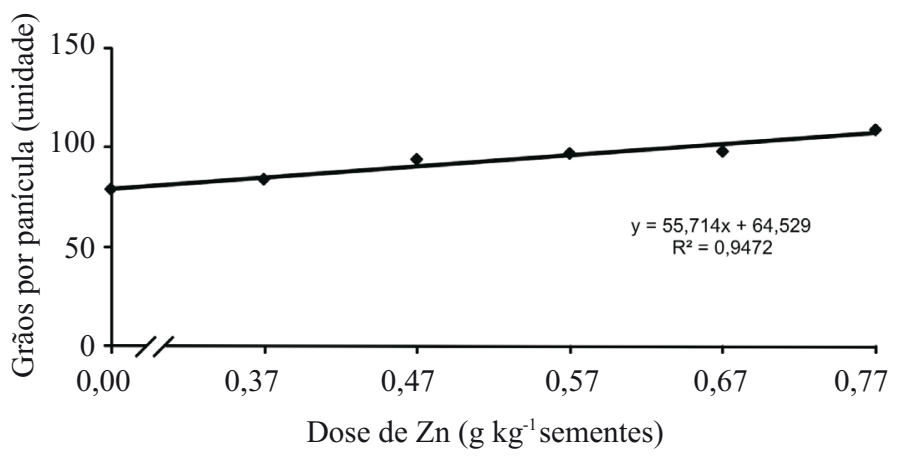

FIGURA 5. Número de grãos por panícula (unidade), de arroz irrigado cv. 417, recobertas com diferentes doses de sulfato de zinco heptahidratado.

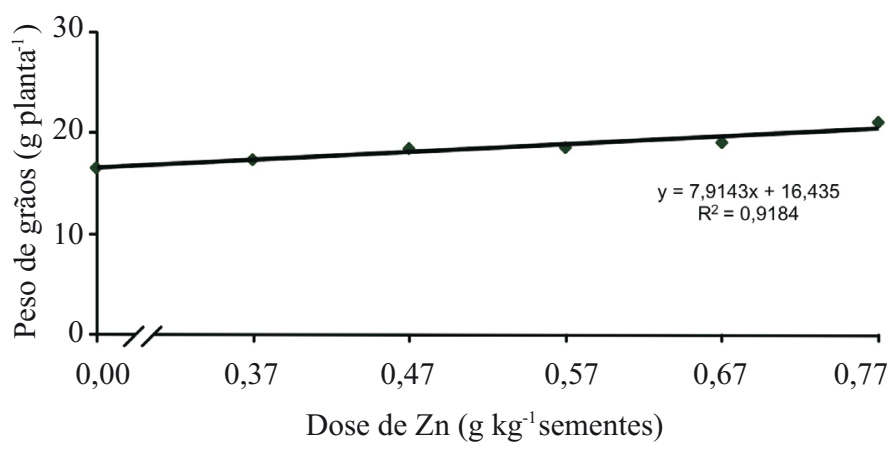

FIGURA 6. Peso de grãos (g planta $\left.{ }^{-1}\right)$ de arroz irrigado cv. 417, recobertas com diferentes doses de sulfato de zinco heptahidratado.

\section{CONCLUSÕES}

O recobrimento de sementes de arroz com o zinco, dosagem de $0,77 \mathrm{~g} \mathrm{~kg}^{-1}$ de semente, aumenta o número de grãos por panícula e peso de grãos por planta em condições de casa de vegetação.

Sementes de arroz recobertas com zinco geram plântulas com maior crescimento.

O recobrimento das sementes com zinco não afeta a germinação. 


\section{REFERÊNCIAS}

AZAMBUJA, I.H.V.; VERNETTI JR. F.J.; MAGALHÃES JR.; A.M. Aspectos socioeconômicos da produção de arroz. In: GOMES, A da S.; MAGALHÃES JÚNIOR, A.M. de (Ed.). Arroz irrigação no sul do Brasil. Brasília, DF: Embrapa Informação e tecnologia, 2004. p.23- 44.

BARBOSA FILHO, M.P.; DYNIA, J.F.; FAGERIA, N.K. Zinco e ferro na cultura do arroz. Embrapa-SPI, Brasília, DF, 1994, 71p.

BONNECARRÈRE, R.A.G.; LONDERO, F.A.A.; SANTOS, O; SCHMIDT, D.; PILAU, F.G. MANFRON, P.A.; NETO, D.D. Resposta de genótipos de arroz irrigado à aplicação de zinco. Revista Faculdade Zootecnia Veterinária e Agronomia, v.10, n.1, p.214- 222, 2004.

BRASIL. Ministério da Agricultura e Reforma Agrária. Secretaria Nacional de Defesa Agropecuária. Departamento Nacional de Defesa Vegetal. Coordenação de Laboratório Vegetal. Regras para análise de sementes. Brasília, DF, 1992. 365p.

COMISSÃO DE QUÍMICA E FERTILIDADE DO SOLO - RS/SC. Manual de adubação e calagem para os Estados do Rio Grande do Sul e de Santa Catarina. 10.ed. Porto Alegre, SBCS - Núcleo Regional Sul/UFRGS, 2004. 400p.

COMPANHIA NACIONAL DE ABASTECIMENTO CONAB. Acompanhamento da safra Brasileira: grãos. Safra 2008/2009 - Nono Levantamento 41p. - junho/2009. Brasília 2009. Disponível em: <http://www.conab.gov.br/ dowload/safra/boletim/safra.pdf $>$. Acesso em: 17 jun. 2009.

EPSTEIN, E.; BLOOM, A.J. Nutrição mineral de plantas, princípios e perspectivas. Traduzido por Maria Edna Tenório Nunes. Londrina, 2006. 86p.

FAGERIA, N.K.; BALIGAR, V.C. Growth components and zinc recovery efficiency of upland rice genotypes. Pesquisa Agropecuária Brasileira, v.40, n.12, p.1211- 1215, 2005.

FAVARIN, J.L.; MARINI, J.P. Importância dos micronutrientes para a produção de grãos. Sociedade Nacional de Agricultura, 2000. Disponível em: <http:// alternex.com.br/ snafagram/artigos/artitec-micronutrientes. htm>. Acesso em: 20 jun. 2008.

IRGA. Instituto Riograndense do Arroz. Censo 2008. Disponível em: <http://www.irga.rs.gov.br/Apresentacao_ Censo_2008.pdf $>$. Acesso em: 10 mai. 2009.

LEÃO, R.M.A. Efeitos do fósforo e do zinco no comportamento do arroz de sequeiro em Latossolo Vermelho Escuro sob vegetação de cerrado. 1990. 124f. Dissertação (Mestrado em Ciência do Solo) - Universidade Federal de Santa Maria, Santa Maria, 1990.
LOPES, A.S. Micronutrientes: filosofias de aplicação e eficiência agronômica. São Paulo. ANDA, 1999. 72p. (Boletim Técnico, 8).

KRZYZANOWSKI, F.C. Teste de comprimento de raiz de plântulas de soja. Informativo ABRATES, v.1, n.1, p.11-14. 1991.

MALAVOLTA, E. Manual de nutrição mineral de plantas. Viçosa: UFV, 2006. 631p.

MARCHESAN, E.; SANTOS, O.S.; AVILA, L.A.; SILVA, R.P. Adubação foliar com micronutrientes em arroz irrigado, em área sistematizada. Ciência Rural, v.31, n.6, p.969-972, 2001.

MORAES, M.F.; SANTOS, M.G.; BERMÚDESZAMBRANO, O.D.; MALAVOLTA, M.; RAPOSO, R.W.; CABRAL, C.P.; MALAVOLTA, E. Resposta do arroz em casa de vegetação a fontes de micronutrientes de diferentes granulometria e solubilidade. Pesquisa Agropecuária Brasileira, v.39, n.6, p.611-614, 2004.

OHSE, S.; MARODIM, V.; SANTOS, O.S.; LOPES, S.J.; MANFRON, P.A. Germinação e vigor de sementes de arroz irrigado tratadas com zinco, boro e cobre. Revista Faculdade Zootecnia Veterinária e Agronomia, v.7, n.1, p.73-79, 2000.

OHSE, S.; SANTOS, S.J.; MARODIM, V.; MANFRON, P.A. Efeito do tratamento de sementes de arroz irrigado com zinco em relação à aplicação no substrato. Revista Faculdade Zootecnia Veterinária e Agronomia, v.5, n.1, p.35-41, 1998.

OLIVEIRA, S.C.; COSTA, M.C.G.; CHAGAS, R.C.S.; FENILLI, T.A.B.; HEINRICHS, R.;CABRAL, C.P.; MALAVOLTA, E. Resposta de duas cultivares de arroz a doses de zinco aplicado como oxissulfato. Pesquisa Agropecuária Brasileira, v.38, n.3, p.387-396, 2003.

RIBEIRO, N.D.; SANTOS, O.S. Aproveitamento do zinco aplicado na semente na nutrição da planta. Ciência Rural, v.26, n.1, p.159-165, 1996.

ROZANE, D.E.; PRADO, R.M.; SIMÕES, R.R.; ROMUALDO, L.M. Resposta de plântulas de arroz cv. BRSSoberana à aplicação de zinco via semente. Revista Ciência Agrotécnica, v.32, n.3, p.847-854, 2008.

SAS Institute. SAS/STAT User's Guide 8.2, Cary, NC: SAS Institute Inc., 1999.

SILVA, L.S.; SOUSA, R.O.; BOHNEN, H. Alterações nos teores de nutrientes em dois solos alagados, com e sem plantas de arroz. Ciência Rural, v.33, n.3, p.487-490, 2003.

SLATON,N.S.;WILSONJUNIOR,C.E.;NTAMATUNGIRO, S.; NORMAN, R.J.; BOOTHE, D.L.; Evaluation of zinc seed treatments for rice. Agronomy Journal, v.93, n.1, p.152- 
157, 2001.

VIEIRA, E.H.N.; MOREIRA, G.A. Peletização de sementes

de arroz. Santo Antônio de Goiás: Embrapa Arroz e Feijão,
2005, 2p. (Embrapa Arroz e Feijão. Comunicado Técnico, 111). 